\title{
Models for Population Growth Curves
}

\author{
L. L. Eberhardt ${ }^{1}$ and J. M. Breiwick ${ }^{2}$ \\ ${ }^{1} 2528$ West Klamath, Kennewick, WA 99336, USA \\ ${ }^{2}$ National Marine Mammal Laboratory, Alaska Fisheries Science Center, NOAA Fisheries Service, 7600 Sand Point Way NE, \\ Seattle, WA 98115, USA
}

Correspondence should be addressed to J. M. Breiwick, jeff.breiwick@noaa.gov

Received 18 October 2011; Accepted 20 November 2011

Academic Editor: G. Wang

Copyright ( 2012 L. L. Eberhardt and J. M. Breiwick. This is an open access article distributed under the Creative Commons Attribution License, which permits unrestricted use, distribution, and reproduction in any medium, provided the original work is properly cited.

We examined models for population growth curves, contrasting integrated versions with various other forms. A sizable number of data sets for birds and mammals were considered, but the main comparisons were based on 27 data sets that could be fit to the generalized logistic curve. Akaike's information criterion was used to rank fits of those data sets to 5 integrated models. We found that the integrated models gave the best fits to the data examined. The difference equations examined gave much poorer fits as judged by AICc and coefficients of variation. We conclude that the integrated models should be used when possible.

\section{Introduction}

Most recent use of population growth curves has focused on difference equation models (also called "finite population models"). Such models may give a somewhat wider scope for applications and for theory, than do the integrated versions of these models. However, the available integrated versions appear to give much better fits to actual growth curve data, raising some questions about the practical utility of the difference equation versions. We thus examine a number of integrated and difference equation models in this paper. The data used are for birds and mammals. Rather different results may apply for insects and some species of fish.

\section{Methods}

2.1. Models. The first of the integrated models used here, the generalized logistic reported by Nelder [16] and by Pella and Tomlinson [17], but best known from Ayala et al. [18], and often termed the theta-logistic is:

$$
N(t)=\left[K^{-z}-\left(K^{-z}-N_{0}^{-z}\right) e^{-r z t}\right]^{-1 / z} .
$$

The corresponding difference equation is

$$
N(t)=N(t-1)+r N(t-1)\left[1-\left(\frac{N(t-1)}{K}\right)^{z}\right] .
$$

A rearrangement of (2) is designated here as the "Sibly model" [19-22]:

$$
\operatorname{pgr}=\left[\left(\frac{N(t)}{N(t-1)}\right)-1\right]=r\left[1-\left(\frac{N(t-1)}{K}\right)^{z}\right] .
$$

The Gompertz curve is

$$
N(t)=K \exp \left(\log \left(\frac{N_{0}}{K}\right) e^{-c t}\right) .
$$

The difference equation in the form used by Dennis et al. [23] is

$$
N(t)=N(t-1) \exp (r+b \log (N(t-1))) .
$$

The logistic growth curve is obtained by setting $z=1$ in (1):

$$
N(t)=\frac{K}{1+c e^{-r t}}, \quad c=\frac{K}{N_{0}}-1 .
$$

The difference equation is

$$
N(t)=N(t-1)+r N(t-1)\left[1-\left(\frac{N(t-1)}{K}\right)\right] .
$$

The exponential model is

$$
N(t)=N_{0} \exp (r t) .
$$


TABLE 1: Comparison of the generalized logistic (1) with the corresponding difference equation (2) and the ordinary logistic (6) compared with the corresponding difference equation (7). Numbers in square brackets refer to references and other numbers are GPDD numbers. Values given are residual mean squares from the fits.

\begin{tabular}{|c|c|c|c|c|c|c|}
\hline Source & $\begin{array}{c}\text { Generalized } \\
\text { logistic }\end{array}$ & $\begin{array}{c}\text { Difference } \\
\text { equation }\end{array}$ & Ratio & Logistic & $\begin{array}{l}\text { Difference } \\
\text { equation }\end{array}$ & Ratio \\
\hline Red deer 6585 & 2.16 & 2.47 & 1.14 & 3.1 & 2.8 & 0.90 \\
\hline Gray fox 319 & 283 & 591 & 2.09 & 378.2 & 566.7 & 1.50 \\
\hline Gray fox 342 & 1311 & 1440 & 1.10 & 1254 & 1399 & 1.12 \\
\hline Coyote 263 & 2528 & 2729 & 1.08 & 2451 & 2681 & 1.09 \\
\hline Gray seals [1] & 56.83 & 93.2 & 1.64 & 65.93 & 90.88 & 1.38 \\
\hline Bison [2] & 5.81 & 7.86 & 1.35 & 5.64 & 7.81 & 1.38 \\
\hline Macaque 6068 & 1.11 & 1.32 & 1.19 & 1.45 & 1.43 & 0.99 \\
\hline Beaver 151 & 15960 & 16490 & 1.03 & 15850 & 16410 & 1.04 \\
\hline Beaver 156 & 40960 & 43800 & 1.07 & 43400 & 44070 & 1.02 \\
\hline Elephant seals [3] & 48.61 & 63.44 & 1.31 & 50.06 & 62.79 & 1.25 \\
\hline Seneca deer [4] & 29.93 & 50.78 & 1.70 & 28.99 & 50.44 & 1.74 \\
\hline Badger 78 & 375 & 453 & 1.21 & 372.5 & 438.8 & 1.18 \\
\hline Gentoo penguins (Fraser pers. comm.). & 61.19 & 113.2 & 1.85 & 57.88 & 108.6 & 1.88 \\
\hline Polar bear 143 & 89.9 & 68.1 & 0.76 & 95.09 & 67.49 & 0.71 \\
\hline Coyote 247 & 308 & 380 & 1.23 & 335.7 & 362.4 & 1.08 \\
\hline Gray fox 328 & 549.3 & 901.3 & 1.64 & 526.1 & 850.1 & 1.62 \\
\hline Marten 9695 & 17020 & 22010 & 1.29 & 16630 & 22390 & 1.35 \\
\hline Squirrel 9699 & 347100 & 393400 & 1.13 & 339100 & 398500 & 1.18 \\
\hline Gray fox 334 & 3383 & 3332 & 0.98 & 3280 & 3155 & 0.96 \\
\hline Camargue horses [5] & 0.58 & 1 & 1.72 & 1.42 & 1.74 & 1.23 \\
\hline Argentine horses [6] & 5.01 & 8.04 & 1.60 & 5.38 & 7.8 & 1.45 \\
\hline Przewalski's horses $[5,7]$ & 0.89 & 1.39 & 1.56 & 1.23 & 1.47 & 1.20 \\
\hline Red kite [8] & 3.27 & 4.56 & 1.39 & 3.2 & 4.46 & 1.39 \\
\hline Medians and Mean Ratios & 89.9 & 113.2 & 1.35 & 95.09 & 108.6 & 1.20 \\
\hline
\end{tabular}

TABLE 2: Contrast of fit to Gompertz (4) with difference equation (5) using residual mean squares.

\begin{tabular}{lccc}
\hline Source & Gompertz & $\begin{array}{c}\text { Difference } \\
\text { equation }\end{array}$ & Ratio \\
\hline Red deer 6585 & 4.01 & 3.5 & 0.87 \\
Gray seals [1] & 68.58 & 91.91 & 1.34 \\
Bison [2] & 6.34 & 7.59 & 1.20 \\
Macaque 6068 & 1.57 & 1.5 & 0.96 \\
Beaver 156 & 46930 & 46160 & 0.98 \\
Elephant seals [3] & 62.24 & 69.86 & 1.12 \\
Seneca deer [4] & 35.4 & 53.87 & 1.52 \\
Badger 78 & 392.7 & 487 & 1.24 \\
Gray fox 328 & 569.8 & 867.9 & 1.52 \\
Marten 9695 & 16850 & 23060 & 1.37 \\
Camargue horses [5] & 1.84 & 2.49 & 1.35 \\
Argentine horses [6] & 5.67 & 8.18 & 1.44 \\
Przelwalski's horses [5, 7] & 1.4 & 1.68 & 1.20 \\
\hline Mean & & & 1.24 \\
\hline
\end{tabular}

The difference equation is

$$
N(t)=N(t-1)+r N(t-1) .
$$

The equation of Morris and Doak [24] is

$$
\hat{\mu}=\left(\frac{1}{q}\right) \sum_{i=0}^{q-1} \log \left(\frac{N_{i+1}}{N_{i}}\right)
$$

with variance estimate:

$$
\operatorname{var} \hat{\mu}=\left(\frac{1}{q-1}\right) \sum_{i=0}^{q-1}\left(\log \left(\frac{N_{i+1}}{N_{i}}\right)-\hat{\mu}\right)^{2}
$$

In the notation used here $\mu=r$. A modification of (1), with $z=2$, is considered here, as it has significant advantages. It is here denoted as a modified logistic:

$$
N(t)=\left[K^{-2}-\left(K^{-2}-N_{0}^{-2}\right) e^{-2 r t}\right]^{-1 / 2} .
$$

In the aforementioned models, $K$ is the asymptotic value, $r$ is a rate of increase, $z$ is the parameter controlling the inflection point in a growth curve, $N_{0}$ represents initial population size, and $b$ and $c$ are functions of $r$ and $K$ in the Gompertz equations. The models have been fit by using nonlinear leastsquares, [25], as implemented in the R-language [26]. 
TABle 3: Contrasts between the Sibly model (3) and the corresponding difference equation (2). Due to structural differences in the models, coefficients of variation are used for contrasts. An asterisk $\left(^{*}\right)$ indicates cases where counts reached or closely approximated an asymptotic value $(K)$.

\begin{tabular}{|c|c|c|c|c|c|}
\hline Source & $\begin{array}{c}\text { Difference equation } \\
\mathrm{K}\end{array}$ & $\mathrm{CV}(\mathrm{K})$ & $\begin{array}{l}\text { Sibly model } \\
\mathrm{K}\end{array}$ & $\mathrm{CV}(\mathrm{K})$ & $\begin{array}{c}\text { Generalized logistic } \\
\mathrm{K}\end{array}$ \\
\hline Red deer $6585^{*}$ & 166 & 0.020 & 167 & 0.028 & 168 \\
\hline Gray fox $319^{*}$ & 10520 & 0.052 & 10760 & 0.574 & 10600 \\
\hline Gray fox $342 *$ & 15590 & 0.003 & 15060 & 0.139 & 15290 \\
\hline Coyote $263^{*}$ & 19340 & 0.063 & 19120 & 0.173 & 19110 \\
\hline Gray seals* [1] & 2044 & 0.155 & 2016 & 0.167 & 2013 \\
\hline Bison [2] & 2120 & 1.314 & no fit & & 1356 \\
\hline Macaque $6068^{*}$ & 24 & 0.026 & 24 & 0.054 & 24 \\
\hline Beaver $151^{*}$ & 156400 & 0.055 & 158500 & 0.057 & 164.500 \\
\hline Beaver $156^{*}$ & 422700 & 0.069 & 429300 & 0.083 & 421200 \\
\hline Elephant seals [3] & 1752 & 0.072 & no fit & & 1862 \\
\hline Seneca deer $[4]$ & 4134 & 0.396 & 2672 & 0.343 & 4425 \\
\hline Badger 78 & 2550 & 0.162 & no fit & & 3009 \\
\hline Gentoo penguins (Fraser pers comm.) & 949 & 0.534 & no fit & & 1027 \\
\hline Polar bear 143 & 738 & 0.097 & no fit & & 700 \\
\hline Coyote $247^{*}$ & 3273 & 0.046 & 3310 & 0.103 & 3231 \\
\hline Gray fox 328 & 9200 & 0.296 & no fit & & 9723 \\
\hline Marten 9695 & 98330 & 0.062 & no fit & & 104000 \\
\hline Squirrel 9699* & $2.19 E+06$ & 0.069 & $2.04 E+06$ & 0.199 & $2.17 E+06$ \\
\hline Gray fox 334 & $3.59 E+05$ & 0.059 & $3.54 E+05$ & 0.217 & 22790 \\
\hline Camargue horses* [5] & 75 & 0.031 & 77 & 0.074 & 78 \\
\hline Argentine horses* $[6]$ & 209 & 0.051 & 209 & 0.069 & 213 \\
\hline Przewalski's horses* $[5,7]$ & 44 & 0.093 & 43 & 0.131 & 44 \\
\hline Red kite [8] & 139 & 7.45 & no fit & & 182 \\
\hline
\end{tabular}

2.2. Akaike's Information Criterion. AIC is calculated as [27]

$$
\mathrm{AIC}=n \log \hat{\sigma}^{2}+2 k, \quad \text { where } \hat{\sigma}^{2}=\frac{\sum \hat{e}_{i}^{2}}{n},
$$

the $\hat{e}_{i}$ are deviations (residuals) from the model fit (assumed to be normally distributed), $n$ is sample size, and $k$ is the number of parameters in the model plus 1 . Most of the available data sets have small samples, so Burnham and Anderson [27] recommended using

$$
\mathrm{AIC}_{c}=\mathrm{AIC}+\frac{2 k(k+1)}{n-k-1} .
$$

Model comparisons are made using

$$
\Delta_{i}=\mathrm{AIC}_{c}-\mathrm{AIC}_{\min },
$$

where $\mathrm{AIC}_{\text {min }}$ is the minimum value calculated for a set of models.

2.3. Data Sources. Part of the data used here was obtained in 2006 from the Global Population Dynamics Database (GPDD) maintained by the National Environmental Research Council at http://www.sw.ic.ac.uk/cpb/gpdd.html. ID numbers for data used from the GPDD appear in the tables. Data sets from the GPDD were obtained by searching the entire data set (over 4000 entries) by inspecting plots of each data set and attempting to fit curves. An up-to-date version of the GPDD data was obtained in 2008 and searched for additional examples. Over 100 data sets were examined in detail, but those that could be fit to (1) are the primary data sets used here.

\section{Results}

3.1. Integrated Models versus Difference Equations. Table 1 contrasts the generalized logistic (1) with the corresponding difference equation (2), and the ordinary logistic (6) with its corresponding difference equation (7), using residual mean squares in consequence of the experience of Eberhardt et al. [28], who found that residual mean squares performed better on data similar to those used here. We believe that the "adjustment factor" of Burnham and Anderson [27] (in (14)) may discriminate against models with the larger number of parameters. In nearly all instances, the integrated version is to be preferred, as shown by residual mean squares. The two apparent exceptions in Table 1 have highly variable data.

Table 2 makes the same contrast for the Gompertz equation (4) with the corresponding difference equation (5). 
TABLE 4: Estimates of the parameter $z$ in (1).

\begin{tabular}{lcc}
\hline Species & $z$ & CV \\
\hline Red deer 6585 & 3.89 & 0.720 \\
Boar 9428 & 4.99 & 1.138 \\
Gray fox 319 & 3.78 & 0.407 \\
Gray fox 342 & 1.85 & 1.151 \\
Coyote 263 & 1.93 & 1.482 \\
Gray seals [1] & 11.76 & 0.882 \\
Bison [2] & 0.75 & 0.627 \\
Macaque 6068 & 16.26 & 1.545 \\
Beaver 151 & 0.46 & 1.739 \\
Beaver 156 & 7.43 & 1.027 \\
Elephant seals [3] & 1.86 & 0.360 \\
Seneca deer [4] & 0.69 & 0.652 \\
Badger 78 & 1.76 & 2.290 \\
Fur seals [9] & 4.05 & 0.783 \\
Blue Springs manatees [10] & 5.08 & 2.108 \\
Chinstrap penguins (Fraser, pers. commun.) & 0.45 & 5.778 \\
Gentoo penguins (Fraser, pers. commun.) & 0.69 & 2.087 \\
Polar bear 143 & 6.13 & 1.127 \\
Coyote 247 & 6.42 & 1.673 \\
Gray fox 328 & 1.88 & 1.293 \\
Boar 9429 & 1.66 & 0.596 \\
Marten 9695 & 1.2 & 1.892 \\
Squirrel 9699 & 0.98 & 2.920 \\
Gray fox 334 & 0.45 & 2.480 \\
Camargue horses [5] & 6.06 & 0.240 \\
Argentine horses [6] & 7.99 & 0.95 \\
Przewalski's horses [5, 7] & 6.81 & 0.690 \\
Red kite [8] & 1.47 & 3.380 \\
\hline Median & 1.93 & \\
\hline
\end{tabular}

Smaller samples are available due to the fact that the Gompertz did not fit a number of the data sets. That the "Sibly" model gives even more variable results is illustrated in Table 3, where the Sibly model (3) has a larger coefficient of variation in all cases where a comparison could be made, with the exception of the Seneca deer data which has essentially an exponential trend.

In those cases marked by an asterisk in Table 3, the estimates of the asymptotic value $(K)$ are nearly the same for the difference equation (2), the Sibly model (3), and the generalized logistic (1). In all of these cases, the data reach an asymptotic value or closely approximate an asymptote. Coefficients of variation (standard error/K) show that the "Sibly" model (3) gives much more variable estimates than do the other two models considered. These are cases where no gaps existed in the count data. The "Sibly" model does not accommodate isolated data points and has to be fit in segments (yielding more variable estimates), whereas the integrated models can be applied directly in such cases.

Table 4 gives estimates of the coefficient $(z)$ governing the inflection point in the generalized logistic model, suggesting

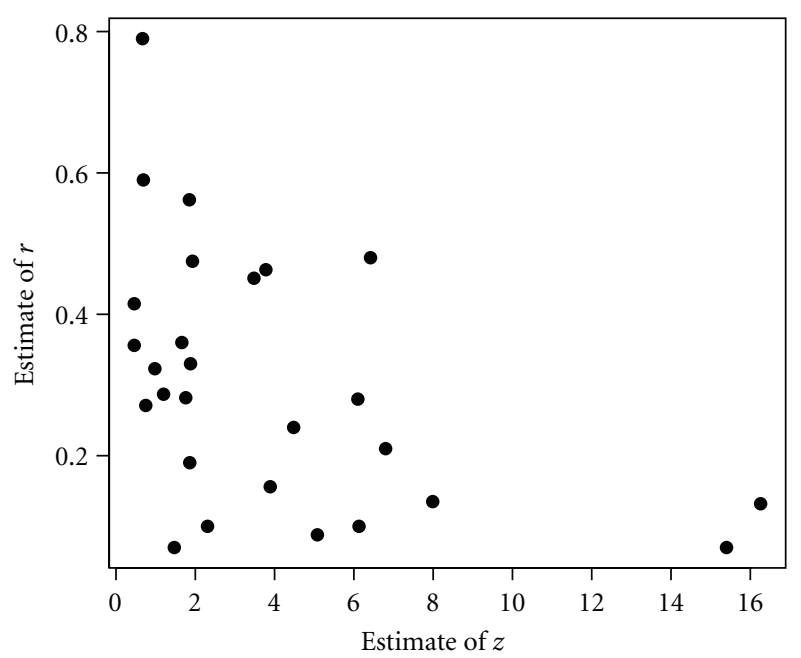

Figure 1: Plot of $r$ versus $z$ from the 27 data sets that fit the generalized logistic model.

use of 2.0 in the modified logistic (12). Table 5 contrasts the 5 integrated models using $\mathrm{AIC}_{c}$, showing that the modified logistic is generally superior. Clark et al. [29] found, using simulations, that there appeared to be a linear relationship between $r$ and $z$ in the generalized logistic model. Using our data set on birds and mammals, we found a correlation between $r$ and $z(-0.51)$ and a distinctly nonlinear relationship. The data appear in Figure 1.

Table 6 compares the Morris and Doak [24] ((10) and (11)) with exponential models fitted by nonlinear leastsquares or a linear fit with log-transformation. The median values indicate that all 3 methods give much the same values, but the Morris and Doak approach is far more variable, as indicated by coefficients of variation. The coefficients of variation show essentially no difference between the two approaches using exponential models. It should be noted that the Morris and Doak estimator (10) can be used with virtually any data set giving nonsensical results in some cases (only exponential-type data were used in Table 6). Thus Morris and Doak [24] used 39 observations on the Yellowstone grizzly bear data, as shown in their Figure 3.6 and Table 3.1. The problem is that the population was initially decreasing and then, as protective measures began to take effect, started to increase in the early $1980 \mathrm{~s}$ and continued to do so for the remainder of the series. Consequently, the resulting estimate of $r$ (or $\mu$ ) is of no practical value. Eberhardt and Breiwick [11] give details and cite 7 published papers that largely ignore the change in trend and thus give largely meaningless results.

3.2. Scope of Models. Clark et al. [29] extracted 99 data sets from the 1198 published by Brook and Bradshaw [20] using a set of criteria that included a minimum number (19) of "transitions" (used because they used difference equations), so all of the data they used had at least 20 observations. This data set contained 42 cases involving birds and mammals, which we screened with linear regression, of which 20 could 
TABLE 5: Contrasting the 5 integrated models using $\mathrm{AIC}_{c}$ and $\Delta_{t}$. Zeros indicate minimum $\mathrm{AIC}_{c}(15)$.

\begin{tabular}{|c|c|c|c|c|c|c|c|}
\hline Species & & $\begin{array}{l}\text { Sample } \\
\text { size }\end{array}$ & $\begin{array}{c}\text { Generalized } \\
\text { logistic }\end{array}$ & $\begin{array}{l}\text { Modified } \\
\text { logistic }\end{array}$ & Logistic & Exponential & Gompertz \\
\hline Red deer 6585 & Cervus elaphus & 13 & 0 & 0.85 & 13.77 & 13.14 & 13.46 \\
\hline Gray seals [1] & Halichoerus grypus & 16 & 0 & 2.17 & 10.67 & 15.21 & 4.62 \\
\hline Beaver 156 & Castor canadensis & 46 & 0 & 0.84 & 10.41 & 52.9 & 6.34 \\
\hline Polar bear 143 & Ursus maritimus & 51 & 0 & 6.3 & 6.3 & 72.75 & no fit \\
\hline Boar 9428 & Sus scrufa & 14 & 2.78 & 0 & 9.37 & 28.37 & 5.2 \\
\hline Gray fox 319 & Urocyon cineroargenteus & 12 & 1.95 & 0 & 12.4 & 37.79 & no fit \\
\hline Gray fox 342 & Urocyon cineroargenteus & 12 & 4.81 & 0 & 7.2 & 27.4 & no fit \\
\hline Coyote 247 & Canis latrans & 11 & 4.46 & 0 & 1.84 & 22.88 & no fit \\
\hline Coyote 263 & Canis latrans & 17 & 3.1 & 0 & 35.68 & 165.69 & no fit \\
\hline Elephant seals [3] & Mirounga angistirostris & 26 & 1.16 & 0 & 10.25 & 61.16 & 13.95 \\
\hline Gray fox 328 & Urocyon cineroargenteus & 12 & 4.81 & 0 & 0.38 & 13.75 & 2.29 \\
\hline Badger 78 & Taxidea tasus & 15 & 2.97 & 0 & 12.37 & 8.47 & 6.71 \\
\hline Fur seals [9] & Callorhinus ursinus & 12 & 3.57 & 0 & 8.37 & 3.47 & 3.47 \\
\hline Blue springs manatees [10] & Trichechus manatus & 19 & 1.6 & 0 & 7.6 & 0.7 & 0.7 \\
\hline Boar 9429 & Sus scrufa & 14 & 3.26 & 0 & 36.04 & 35.97 & 5.09 \\
\hline Camargue horses [5] & Equs caballus & 8 & 7.34 & 0 & 4.53 & 16.97 & 8.6 \\
\hline Przewalski horses $[5,7]$ & Equs ferus & 8 & 14.09 & 0 & 2.1 & 4.18 & 7.67 \\
\hline Marten 9695 & Martes americana & 25 & 1.27 & 0 & 0.99 & 13.37 & 0.27 \\
\hline Squirrel 9699 & Sciuris verginianus & 25 & 1.27 & 1.27 & 0 & 18.23 & 0.65 \\
\hline Bison [2] & Bison bison & 13 & 1.28 & 0.26 & 0 & 23.29 & 0.51 \\
\hline Seneca deer [4] & Odocoileus virginianus & 11 & 2.58 & 5.73 & 0 & 40.94 & 3.52 \\
\hline Gentoo penguins** & Pygoscelis papua & 12 & 5.24 & 5.77 & 0 & 31.14 & 4.4 \\
\hline Beaver 151 & Castor canadensis & 44 & 4.73 & 0.8 & 0 & 13.94 & no fit \\
\hline Chinstrap penguins** & Pygoscelis antarcticus & 22 & 2.77 & 2.22 & 0 & 62.75 & 0.05 \\
\hline
\end{tabular}

** Fraser, pers. comm.

TABle 6: Comparison of Morris and Doak estimates with exponential models.

\begin{tabular}{|c|c|c|c|c|c|c|}
\hline \multirow{2}{*}{ Species } & \multicolumn{2}{|c|}{ Morris and Doak } & \multicolumn{2}{|c|}{ Nonlinear LS } & \multicolumn{2}{|c|}{ Log transform } \\
\hline & $r$ & $\mathrm{CV}$ & $r$ & $\mathrm{CV}$ & $r$ & $\mathrm{CV}$ \\
\hline Grizzlies [11] & 0.055 & 1.440 & 0.054 & 0.137 & 0.056 & 0.126 \\
\hline Bison [2] & 0.203 & 0.08 & 0.188 & 0.037 & 0.201 & 0.03 \\
\hline Muskox [12] & 0.145 & 0.104 & 0.169 & 0.022 & 0.146 & 0.027 \\
\hline Calif. Sea otters D. Siniff, pers. comm. & 0.047 & 0.422 & 0.055 & 0.073 & 0.052 & 0.076 \\
\hline Gray seals [1] & 0.066 & 0.256 & 0.068 & 0.054 & 0.069 & 0.041 \\
\hline Albatross [13] & -0.007 & 3.260 & -0.008 & 0.290 & -0.008 & 0.302 \\
\hline Sparrow [14] & -0.061 & 0.477 & -0.055 & 0.094 & -0.052 & 0.088 \\
\hline Red kite [8] & 0.058 & 0.320 & 0.058 & 0.035 & 0.059 & 0.034 \\
\hline YNP Bison [15] & 0.163 & 0.112 & 0.141 & 0.024 & 0.156 & 0.028 \\
\hline Seneca deer [4] & 0.391 & 0.080 & 0.386 & 0.068 & 0.411 & 0.003 \\
\hline Medians & 0.058 & 0.256 & 0.058 & 0.054 & 0.059 & 0.034 \\
\hline
\end{tabular}

be fit with the modified logistic (12) or with an exponential model (4 cases). Those that did not have significant slopes were examined with (10) and appeared to be essentially stationary series (correlation $=0$ ) with the exception of a few instances (3) with an erratic pattern. There were just 4 cases in the Clark data that also fell in our sample (Fulmar 6527, Blue Wildebeest 7060, Sandhill crane 9990, and Blue tit 6830).

\section{Discussion}

The results given here indicate that, for any practical purposes, the integrated models should be used for species like those considered here (birds and mammals). The Gompertz model may be preferred for some species of fish and for insects. Our analyses here have largely been restricted to data sets that can be fit by the generalized logistic (1). The 
modified logistic (12) and the ordinary logistic (6) can be fit to a much wider range of data. In a few cases, the exponential (8) may appear to give a better fit, but these appear to be largely instances where the data are limited to the early stages of population increase.

The recent ecological literature contains a wide range of difference equations (finite population growth models). We have studied 5 of these [28], but there are additional examples [20-23, 30-35]. One reason for the popularity of difference equation models is that they provide a wide range of models, some of which have no integrated analogs. A popular example is the Ricker model $[36,37]$ :

$$
N(t)=N(t-1) \exp \left(r\left[1-\frac{N(t-1)}{K}\right]\right)
$$

where $r$ is the rate of increase and $\mathrm{K}$ the asymptotic value, as before. This model was originally developed for cases where $r$ is quite large and thus may be useful for such situations. If $r$ is not large (as in all of the cases examined here), the model reduces to the difference equation version of the ordinary logistic, so that the ordinary logistic or (preferably the modified logistic) can be used. There may thus be some practical reasons to consider difference equations. In many other cases, it appears that the principal goals are the development of ecological theory.

\section{References}

[1] W. N. Bonner, "Population increase of grey seals at the Farne Islands. Biology of the Seal," in Rapports et Proces-Verbaux des Reunions, Conseil International pour l'Exploration de la Mer, K. Ronald and A. W. Mansfield, Eds., vol. 169, pp. 366-370, 1975.

[2] R. A. Fredin, "Levels of maximum net productivity in populations of large terrestrial mammals," in Reproduction in Whales, Dolphins and Porpoises, W. F. Perrin, R. L. Brownell Jr., and D. P. DeMaster, Eds., Special Issue 6, pp. 381-387, Reports of the International Whaling Commission, Cambridge, UK, 1984.

[3] B. S. Stewart, P. K. Yochem, H. R. Huber et al., "History and present status of the northern elephant seal population," in Elephant Seals: Population Ecology, Behavior, and Physiology, B. J. Le Bouef and R. M. Laws, Eds., pp. 29-48, University of California Press, Berkeley, Calif, USA, 1994.

[4] W. T. Hesselton, C. W. Sevringhaus, and J. E. Tanck, "Population dynamics of deer in the Seneca army depot," New York Fish and Game Journal, vol. 12, pp. 17-30, 1965.

[5] S. Grange, P. Duncan, and J. M. Gaillard, "Poor horse traders: large mammals trade survival for reproduction during the process of feralization," Proceedings of the Royal Society B: Biological Sciences, vol. 276, no. 1663, pp. 1911-1919, 2009.

[6] A. L. Scorolli and A. C. L. Cazorla, "Demography of feral horses (Equus caballus): a long-term study in Tornquist Park, Argentina," Wildlife Research, vol. 37, no. 3, pp. 207-214, 2010.

[7] L. Tatin, S. R. B. King, B. Munkhtuya, A. J. M. Hewison, and C. Feh, "Demography of a socially natural herd of Przewalski's horses: an example of a small, closed population," Journal of Zoology, vol. 277, no. 2, pp. 134-140, 2009.

[8] P. E. Davis and J. Newton, "Population and breeding of red kites in Wales over a 30 year period," Journal of Animal Ecology, vol. 50, pp. 759-772, 1981.
[9] K. W. Kenyon, V. B. Scheffer, and D. G. Chapman, "A population study of the Alaska fur seal herd," Special Scientific Report wildlife no. 12, United States Department of the Interior, U. S. Fish and Wildlife Service, Washington, DC, USA, 1954.

[10] L. L. Eberhardt and T. J. O'Shea, "Integrating manatee life history data and population model development. Population biology of the Florida manatee," in Information and Technology Report 1, T. J. O'Shea, B. B. Ackerman, and H. F. Percival, Eds., Technical Report Series, pp. 269-278, National Biological Service, Ft. Collins, Colo, USA, 1995.

[11] L. L. Eberhardt and J. M. Breiwick, "Trend of the Yellowstone grizzly bear population," International Journal of Ecology, vol. 2010, Article ID 924197, 5 pages, 2010.

[12] D. L. Spencer and C. J. Lensink, "The muskox of Nunivak Island, Alaska," Journal of Wildlife Management, vol. 34, pp. $1-15,1970$.

[13] J. P. Croxall, P. Rothery, S. P. C. Pickering, and P. A. Prince, "Reproductive performance, recruitment and survival of wandering albatrosses Diomedea exulans at Bird Island, South Georgia," Journal of Animal Ecology, vol. 59, no. 2, pp. 775-796, 1990.

[14] K. J. Gaston, "Valuing common species," Science, vol. 327, no. 5962, pp. 154-155, 2010.

[15] J. A. Fuller, R. A. Garrott, and P. J. White, "Emigration and density dependence in Yellowstone bison," Journal of Wildlife Management, vol. 71, no. 6, pp. 1924-1933, 2007.

[16] J. A. Nelder, "The fitting of a generalization of the logistic curve," Biometrics, vol. 17, pp. 89-110, 1961.

[17] J. J. Pella and P. K. Tomlinson, "A generalized stock production model," Bulletin of the Inter-American Tropical Tuna Commission, vol. 13, pp. 419-496, 1969.

[18] F. J. Ayala, M. E. Gilpin, and J. G. Ehrenfeld, "Competition between species: theoretical models and experimental tests," Theoretical Population Biology, vol. 4, no. 3, pp. 331-356, 1973.

[19] R. M. Sibly, D. Barker, M. C. Denham, J. Hone, and M. Pagel, "Ecology: on the regulation of populations of mammals, birds, fish, and insects," Science, vol. 309, no. 5734, pp. 607-610, 2005.

[20] B. W. Brook and C. J. A. Bradshaw, "Strength of evidence for density dependence in abundance time series of 1198 species," Ecology, vol. 87, no. 6, pp. 1445-1451, 2006.

[21] B. E. Sæther, V. Grøtan, P. Tryjanowski, C. Barbraud, S. Engen, and M. Fulin, "Climate and spatio-temporal variation in the population dynamics of a long distance migrant, the white stork," Journal of Animal Ecology, vol. 75, no. 1, pp. 80-90, 2006.

[22] A. Berryman and M. Lima, "Detecting the order of population dynamics from time series: nonlinearity causes spurious diagnosis," Ecology, vol. 88, no. 8, pp. 2121-2123, 2007.

[23] B. Dennis, J. M. Ponciano, S. R. Lele, M. L. Taper, and D. F. Staples, "Estimating density dependence, process noise, and observation error," Ecological Monographs, vol. 76, no. 3, pp. 323-341, 2006.

[24] W. F. Morris and D. F. Doak, Quantitative Conservation Biology, Sinauer Associates, Sunderland, Mass, USA, 2002.

[25] D. M. Bates and D. G. Watts, Nonlinear Regression Analysis and Its Applications, John Wiley \& Sons, New York, NY, USA, 1988.

[26] R Development Core Team, R: A Language and Environment for Statistical Computing, ISBN 3-900051-07-0, R Foundation for Statistical Computing, Vienna, Austria, 2001.

[27] K. P. Burnham and D. R. Anderson, Model Selection and MultiModel Inference, Springer, New York, NY, USA, 2nd edition, 2002. 
[28] L. L. Eberhardt, J. M. Breiwick, and D. P. DeMaster, "Analyzing population growth curves," Oikos, vol. 117, no. 8, pp. 12401246, 2008.

[29] F. C. Clark, B. W. Brook, S. Delean, H. R. Akçakaya, and C. J. A. Bradshaw, "The theta-logistic is unreliable for modeling most census data," Methods in Ecology and Evolution, vol. 1, pp. 253-262, 2010.

[30] R. P. Freckleton, A. R. Watkinson, R. E. Green, and W. J. Sutherland, "Census error and the detection of density dependence," Journal of Animal Ecology, vol. 75, no. 4, pp. 837851, 2006.

[31] S. Loibel, J. B. R. do Val, and M. G. Andrade, "Inference for the Richards growth model using Box and Cox transformation and bootstrap techniques," Ecological Modelling, vol. 191, no. 3-4, pp. 501-512, 2006.

[32] R. M. Sibly, D. Barker, J. Hone, and M. Pagel, "On the stability of populations of mammals, birds, fish and insects," Ecology Letters, vol. 10, no. 10, pp. 970-976, 2007.

[33] C. P. Doncaster, "Non-linear density dependence in time series is not evidence of non-logistic growth," Theoretical Population Biology, vol. 73, no. 4, pp. 483-489, 2008.

[34] J. P. Buonaccorsi and J. Staudenmayer, "Statistical methods to correct for observation error in a density-independent population model," Ecological Monographs, vol. 79, no. 2, pp. 299-324, 2009.

[35] L. Polansky, P. de Valpine, J. O. Lloyd-Smith, and W. M. Getz, "Likelihood ridges and multimodality in population growth rate models," Ecology, vol. 90, no. 8, pp. 2313-2320, 2009.

[36] W. E. Ricker, "Stock and recruitment," Journal of the Fisheries Research Board of Canada, vol. 11, pp. 559-623, 1954.

[37] W. E. Ricker, "Computation and interpretation of biological statistics of fish populations," Bulletin of the Fisheries Research Board of Canada, vol. 191, pp. 2-6, 1975. 

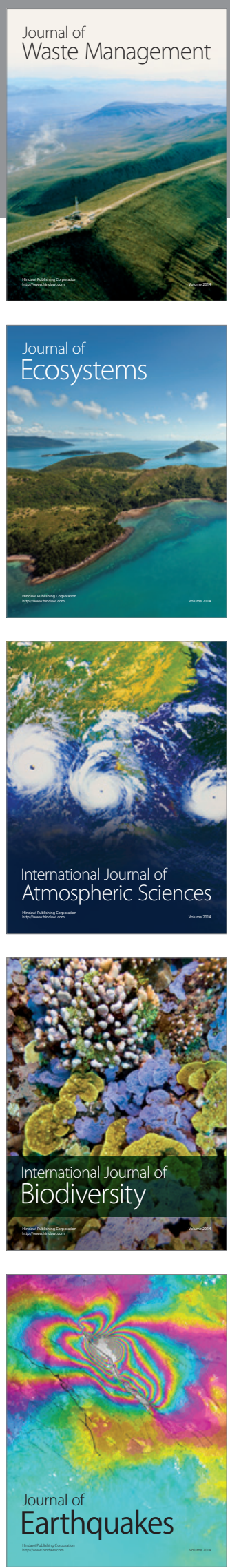
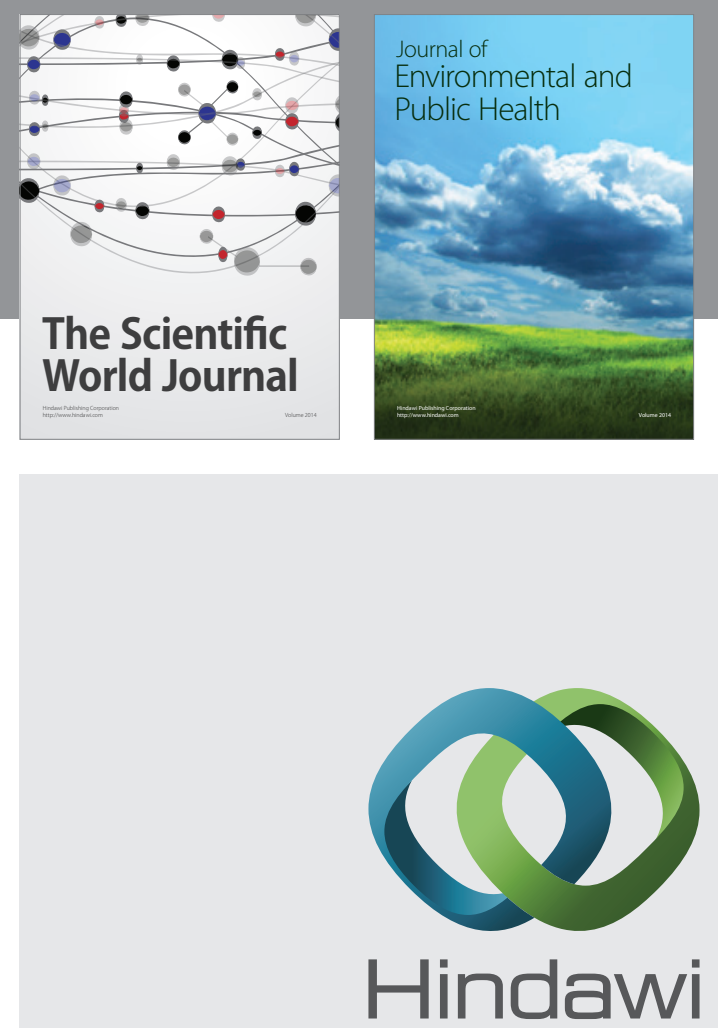

Submit your manuscripts at

http://www.hindawi.com
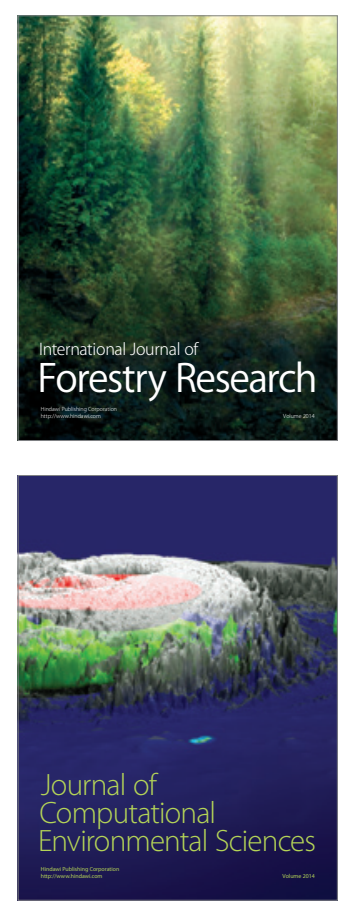
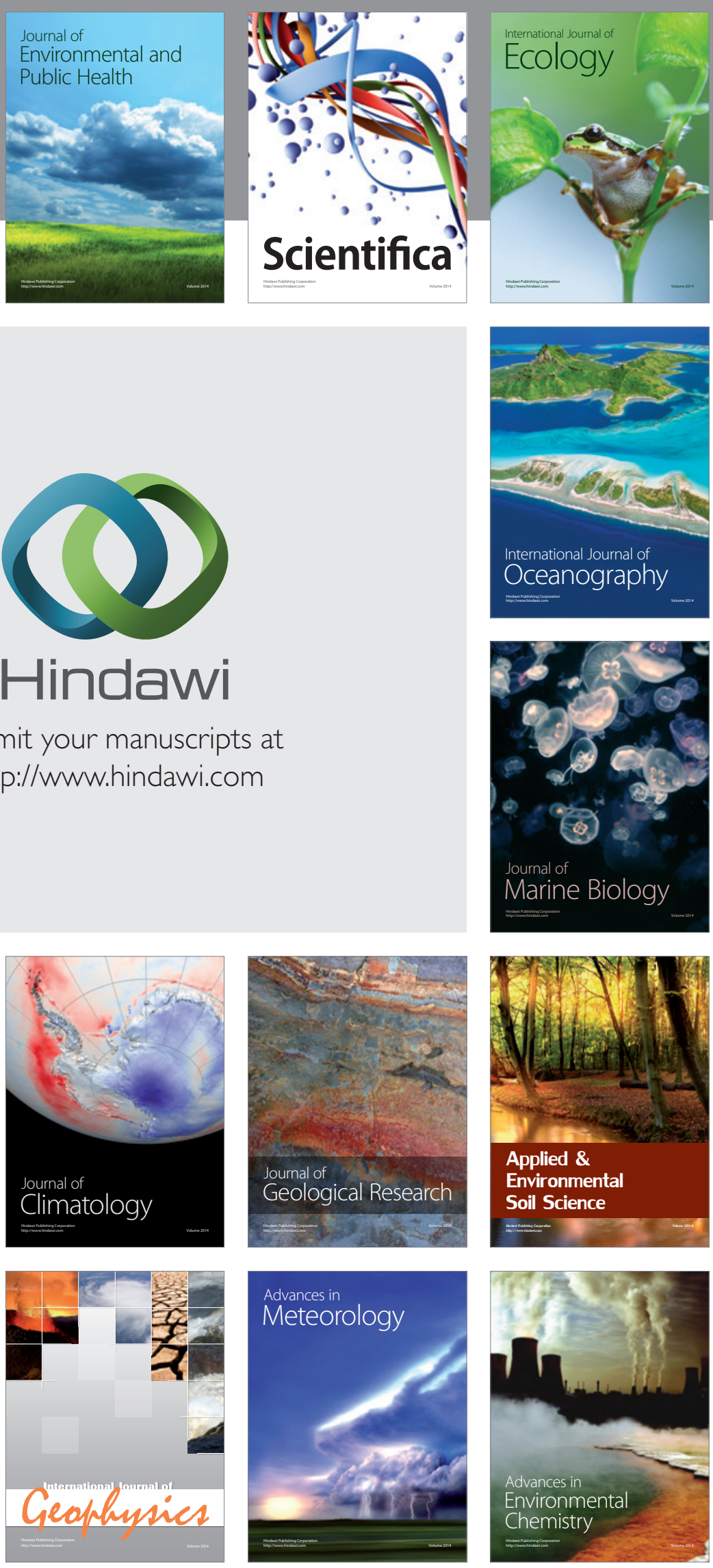